\title{
Holmium Laser Enucleation of the Prostate versus Laparoscopic Transcapsular Prostatectomy: Perioperative Results and Three-Month Follow-Up
}

\author{
Arnaud Baldini $^{\mathrm{a}}$ Hakim Fassi-Fehria ${ }^{\mathrm{a}}$ Ricardo C. Duarte ${ }^{\mathrm{a}}$ Sebastien Crouzet $^{\mathrm{a}}$ \\ René Ecochard ${ }^{\mathrm{b}} \quad$ Nadia Abid $^{\mathrm{a}} \quad$ Xavier Martin $^{\mathrm{a}} \quad$ Lionel Badet $^{\mathrm{a}} \quad$ Marc Colombel $^{\mathrm{a}}$

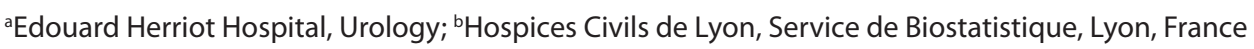

\author{
Key Words \\ Prostatectomy • Laparoscopy • Benign hypertrophy • \\ HoLEP • Hemoglobin
}

\begin{abstract}
Purpose: Symptomatic benign prostatic hypertrophy greater than $70 \mathrm{cc}$ used to be treated by invasive procedures. Holmium laser enucleation of prostate (HoLEP) and laparoscopic transcapsular prostatectomy (LTP) are two techniques whose efficacy has been demonstrated compared to standard onesmore invasive standard procedures. The objective was to evaluate and compare perioperative results from these two techniques for the treatment of benign prostatic hypertrophy greater than $70 \mathrm{cc}$. Methods: This was a non-randomized retrospective study comparing the HoLEP technique with LTP. From January 2012 to January 2015, 39 patients had HoLEP and 28 had LTP. Perioperative outcomes, complications, and functional results at 3 months were compared. A chi-2 squared test and Student's $t$ test were used for statistical analysis. Results: In multivariate analysis, there was a statistically significant difference in favor of HoLEP for the duration of catheterization ( 1.9 vs. 3.7 days; $p=0.004$ ) and the average length of stay ( 2.8 vs. 4.0 days, $p=0.010$ ). There was a trend towards a greater decrease in postoperative hemoglobin levels in LTP (138 vs. $218 \mathrm{~g} / \mathrm{l} ; \mathrm{p}=0.082$ ), which was statistically significant in univariate analysis $(p=$
\end{abstract}

\section{KARGER}

Fax +4161306 1234

E-Mail karger@karger.com

www.karger.com
(C) 2016 S. Karger AG, Basel

Accessible online at: www.karger.com/cur
0.033). Other endpoints were not significant, particularly the enucleated prostate volume compared to the total prostate volume (61.8 vs. $68.4 \% ; p=0.319)$ and postoperative complications. Conclusion: There was no increased morbidity for LTP compared to the HoLEP technique. However, the HoLEP technique appeared to be a less invasive technique, reducing the duration of catheterization, blood loss, and the average length of stay while maintaining good efficacy for the enucleated prostate volume.

Copyright $\odot 2016$ S. Karger AG, Basel

\section{Introduction}

Benign prostatic hypertrophy (BPH) affects more than $80 \%$ of men over 60 years old. It is a benign disease which can lead to significant impairment in the quality of life, requiring treatment and/or surgery [1].

The current standard treatment for complicated or drug treatment-resistant $\mathrm{BPH}$ is endoscopic resection of the prostate for prostates less than $70-80 \mathrm{~g}$, and prostatectomy via open surgery for those over 70-80 g [2].

The holmium laser enucleation of the prostate (HoLEP) technique is a new endoscopic technique for treatment of BPH, initially described by Gilling in 1996 [3]. In addition to its minimally invasive nature, this tech-

Arnaud Baldin

Edouard Herriot Hospital, Urology

5 place d'Arsonval

FR-69003, Lyon (France)

E-Mail abaldini@hotmail.fr 
Table 1. Preoperative characteristics HoLEP versus LTP

\begin{tabular}{llll}
\hline & HoLEP Mean (SEM) & LTP Mean (SEM) & \\
\hline Number & 39 & 28 & $<0.001$ \\
TPV (ml) & $83.9(28.8)$ & $120.5(37.24)$ & 0.549 \\
Age (years) & $69.8(1.33)$ & 8 & 0.364 \\
ASA 1 & 9 & $1.36)$ & 0.364 \\
ASA 2 & 20 & 3 & 0.364 \\
ASA 3 & 10 & 4 & 0.901 \\
AP/VKA & 6 & $19.8(2.55)$ & 0.607 \\
IPSS & $21.1(1.02)$ & $4.0(0.13)$ & 0.764 \\
Discomfort score & $4.4(0.24)$ & $159.4(8.89)$ & 0.702 \\
Qmax (ml/min) & $8.2(0.83)$ & 6 & 0.675 \\
PVR (ml) & $137.1(2.97)$ & $8.4(1.46)$ & 0.928 \\
AUR & 8 & $143.5(3.02)$ & 0.430 \\
PSA pre op $(\mathrm{ng} / \mathrm{ml})$ & $7.2(0.74)$ & & 0.761 \\
Hb pre op $(\mathrm{g} / \mathrm{l})$ & $142.2(2.60)$ &
\end{tabular}

HoLEP = Holmium laser enucleation of the prostate; LTP = laparoscopic transcapsular prostatectomy; TPV = total prostatic volume; ASA = American Society of Anesthesiologists; AP = antiplatelets; VKA = vitamin K antagonist; Qmax = maximum flow; PVR = postvoid residual; $\mathrm{AUR}=$ acute urinary retention; $\mathrm{Hb}=$ hemoglobin; $\mathrm{SEM}=$ standard error of the mean.

nique can treat prostates without volume limitation, with satisfactory and beneficial results, comparable to standard techniques [4].

The renewed interest in prostate enucleation techniques and mastery of laparoscopic radical prostatectomy has led some teams to carry out laparoscopic transcapsular prostatectomy (LTP) using the Millin approach [5], a technique described for the first time by Mariano et al. [6] in 2002.

The use of the da Vinci robot has also been reported for carrying out transcapsular enucleations using the Millin approach [7]. The advantage of laparoscopic surgery is to reproduce open enucleation, whose long-term benefits are known, while minimizing perioperative morbidity.

The purpose of this study was to compare the perioperative results of two minimally invasive techniques for prostatic enucleation performed in patients with lower urinary tract symptoms (LUTS) associated with BPH greater than $70 \mathrm{~g}$ : HoLEP versus LTP.

\section{Materials and Methods}

\section{Population and Methods}

This was a monocentric retrospective observational study comparing the HoLEP technique with LTP. It included patients with symptomatic BPH greater than $70 \mathrm{cc}$, complicated or resistant to medical treatment, operated on between January 2012 and January 2015.
The preoperative assessment of patients included a history, digital rectal examination, PSA assay, a validated IPSS-QOL questionnaire, uroflowmetry with measurement of post-void residual, and a laboratory test for measurement of the hemoglobin $\mathrm{(Hb)}$ level. The total prostate volume was measured by a radiologist with endo-rectal ultrasound.

The perioperative characteristics were noted [operative time, prostatic weight, duration of catheterization, and average length of stay (ALOS)]. The blood loss was recorded (except with HoLEP, for which we were not able to analyze the loss). All patients had $\mathrm{Hb}$ levels measured postoperatively on day 1 , and the $\mathrm{Hb}$ variation was calculated for each patient (pre- and post-operative difference in $\mathrm{Hb}$ ).

Early postoperative complications $(\leq 3$ months postoperatively) were recorded and classified according to the Clavien classification [8].

Patients were seen in consultation at three months, with prostatic functional assessment (clinical examination, PSA, IPSSQOL, uroflowmetry, and measurement of post-void residual).

\section{Surgical Procedure}

Prostatic laser enucleation was performed according to the HoLEP technique originally described by Gilling [3], using a 100 watt Holmium laser. Enucleation is a cystoscopic surgical procedure which needs a holmium laser generator, a specific fiber, and a morcellator. This procedure was performed by a single operator having mastered the learning curve. The enucleated prostate lobes were then morcellated and recovered for histological analysis.

LTP was performed via the peritoneal route, using 3 trocars in addition to the optical trocar ( 1 of $10 \mathrm{~mm}$ and 2 of $5 \mathrm{~mm}$ ). The prostatic capsule was incised transversely, and the cleavage plane of the prostate opened in all planes to allow enucleation. The initial capsular vein ligation time was not necessary, due to 
Table 2. Perioperative characteristics HoLEP versus LTP

\begin{tabular}{|c|c|c|c|c|}
\hline & HoLEP Mean (SEM) & LTP Mean (SEM) & $\mathrm{p}$ (propensity score) & $\mathrm{p}$ \\
\hline Number & 39 & 28 & & \\
\hline Duration of catheterization (days) & $1.9(0.29)$ & $3.7(0.49)$ & 0.004 & 0.004 \\
\hline ALOS (days) & $2.8(0.52)$ & $4.0(0.15)$ & 0.056 & 0.010 \\
\hline Prostate weight (g) & $52.4(4.75)$ & $81.1(6.82)$ & 0.001 & 0.354 \\
\hline $\mathrm{Hb}(\mathrm{g} / \mathrm{l})$ & $13.8(2.27)$ & $21.8(2.81)$ & 0.033 & 0.082 \\
\hline Mean operative time (min) & $106.6(6.71)$ & $115.0(4.74)$ & 0.376 & 0.974 \\
\hline Blood loss (ml) & - & 357.3 & - & - \\
\hline Weight/TPV (\%) & $61.8(4.8)$ & $68.4(2.9)$ & 0.293 & 0.319 \\
\hline Hb post op (g/l) & $129.7(3.75)$ & $119.1(5.29)$ & 0.099 & 0.068 \\
\hline
\end{tabular}

HoLEP = Holmium laser enucleation of the prostate; LTP = laparoscopic transcapsular prostatectomy; ALOS = average length of stay; TPV = total prostatic volume; $\mathrm{Hb}=$ hemoglobin; $\mathrm{SEM}=$ standard error of the mean.

the natural hemostasis caused by the pneumoperitoneum [9-11]. This procedure was performed by a single operator experienced in laparoscopy.

Whichever procedure was done, a 20 or 22 Fr urinary catheter was left in place at the end of the procedure with continuous irrigation. The urinary catheter was removed the day after the stop of bladder irrigation.

\section{Statistical Analysis}

The statistical analysis was based on the comparison of the HoLEP and LTP groups. The qualitative values comparison was performed by the Chi-squared test, and the quantitative values by Student's $t$ test.

A second analysis was performed using a propensity score to correct the effect of non-randomization. Five groups of patients were created, with equal probability in each group to have either the HoLEP or laparoscopic technique. The scores were adjusted for age, American Society of Anesthesiologists (ASA) score, the presence of platelet aggregation inhibitors or anticoagulants, and initial total prostate volume.

Comparison between the HoLEP technique and LTP could result in differences due to patients' characteristics, for example, the choice of technique may be affected by age, ASA score, the presence of platelet aggregation inhibitors or anticoagulants, or initial total prostate volume. Thus, we first used a logistic regression to predict treatment allocation. Then, we classified the patients in 5 categories of increasing values or predicted probability to receive HoLEP. The comparisons were then adjusted for these classes. This method is the so called propensity score method, known to partially protect against indication bias. The low number of subjects in our study is a limitation but did not prevent its utilization.

\section{Results}

A total of 67 patients were included, 39 in the HoLEP group and 28 in the LTP group. The 2 groups were comparable in terms of age, ASA score, treatment with

Comparaison between HoLEP and

Laparoscopic Enucleation of the Prostate platelet aggregation inhibitors or anticoagulants, voiding scores (IPSS-QOL, uroflowmetry, post-void residual), and preoperative hemoglobin. The initial total prostate volume was significantly greater in the LTP group (table $1)$.

No conversion from LTP and HoLEP to open surgery or transurethral resection of the prostate was necessary.

In multivariate analysis, there was a statistically significant difference in favor of the HoLEP group for the duration of catheterization (1.9 vs. 3.7 days; $p=0.004$ ) and the ALOS (2.8 vs. 4.0 days, $\mathrm{p}=0.01)$. There was a trend towards a greater decrease in postoperative hemoglobin levels in the LTP group (138 vs. $218 \mathrm{~g} / \mathrm{l} ; \mathrm{p}=$ 0.082 ), which was statistically significant in univariate analysis $(\mathrm{p}=0.033)$. The operative time (106.6 vs. 115.0 min, $p=0.974)$ and the enucleated volume of the total prostate volume $(61.8$ vs. $68.4 \% ; \mathrm{p}=0.319)$ were not statistically significant in both univariate and multivariate analysis (table 2).

The comparison of postoperative complications was not statistically significant $(p>0.05)$ for all criteria studied, including the transfusion rate [3 $(7.7 \%)$ vs. $1(3.6 \%)]$, the rate of surgical revision, or readmission rates (table 3 ).

No patient was lost to follow-up. At 3 months postoperatively, the Qmax was lower and the IPSS score higher in the HoLEP group, but without significant difference. The PSA level was significantly lower in the LTP group (2.5 vs. $0.6 \mathrm{ng} / \mathrm{ml} ; \mathrm{p}=0.024)$ (table 4). As far as the post-operative complications were concerned, 8 patients $(20.5 \%)$ described urgenturia and pollakiuria with or without incontinence in the HoLEP group, versus 2 patients $(7.1 \%)$ in the LTP group. 
Table 3. Postoperative complications HoLEP versus LTP

\begin{tabular}{lllll}
\hline & HoLEP & LTP & p & (propensity score) \\
\hline Number & 39 & 28 & & 0.744 \\
Clavien & 0.3 & 0.3 & 0.483 & 0.516 \\
Transfusion & 3 & 1 & 0.483 & 0.527 \\
Acute urinary retention & 3 & 1 & 0.305 & 0.355 \\
Clotting & 6 & 1 & 0.761 & 0.809 \\
Urinary infections & 2 & 2 & 0.09 & 0.079 \\
General (chronic atrial fibrillation and ileus) & 0 & 1 & 0.393 & 0.217 \\
Wound complications & 0 & 0 & 0.224 & 0.241 \\
Surgical revision & 1 & 0 & & \\
Re-admission & 2 & & & \\
\hline
\end{tabular}

HoLEP = Holmium laser enucleation of the prostate; LTP = laparoscopic transcapsular prostatectomy.

Table 4. Functional features at 3 months postoperative

\begin{tabular}{lllll}
\hline At 3 months & HoLEP Mean (SEM) & LTP Mean (SEM) & $p$ & p (adjusted for propensity score) \\
\hline Number & 39 & 28 & & 0.193 \\
PSA (ng/ml) & $2.5(0.59)$ & $0.6(0.26)$ & 0.089 & 0.050 \\
IPSS score & $11.3(1.21)$ & $4.6(0.33)$ & 0.248 & 0.358 \\
QOL & $2.8(0.44)$ & $1.1(0.00)$ & 0.328 & 0.246 \\
Qmax (ml/min) & $17.1(1.57)$ & $21.6(3.33)$ & 0.385 & 0.291 \\
PVR (ml) & $58.3(9.70)$ & $25.0(25.00)$ & & \\
\hline
\end{tabular}

PVR = Post-void residual; SEM: standard error of the mean.

\section{Discussion}

\section{Mini Invasive Techniques}

Surgical treatment of BPH has benefited in recent years from the development of new techniques, such as photovaporization or laser enucleation.

HoLEP and LTP have been the subjects of several comparative studies, each demonstrating their benefit compared to open prostatectomy by allowing shorter durations of catheterization and hospital stays, and a reduction in bleeding and perioperative transfusions compared to open surgery [12-15].

This study is the second to our knowledge comparing perioperative results of these 2 minimally invasive prostatic enucleation techniques, the endoscopic one performed with the holmium laser and the other, a surgical one, via the laparoscopic approach. Indeed, a Spanish study has recently shown the same results comparing the 2 procedures [12].

\section{Learning Curve}

Both of these techniques have learning difficulties in common. In this study, the procedures were done by 2 experienced operators in order to reduce the biases related to the learning curve. HoLEP requires an expertise with more than 20 patients, given the difficulty of enucleation and the operative time [13,14], while expertise with at least 10 patients for LTP has been demonstrated sufficient [15]. No conversion to prostatic endoscopic resection in the HoLEP group or to open surgery in the LTP group was observed. Also, operative times were equivalent, with similar efficacy, since the percentage of resected tissue was comparable in both groups (61.8 vs. $68.4 \%$ ).

\section{Morbidity}

One of the main objectives in the development of a minimally invasive technique is to reduce perioperative morbidity for a functional surgery that involves elderly 
patients who often have associated comorbidities. In particular, the hemorrhagic risk from prostatic surgery may lead to cardiac complications, as shown by some studies [16-19]. In this study, only one patient in the HoLEP group had grade IIIb complications according to Clavien, with need for a surgical revision for bladder clot removal. We found no ischemic or thromboembolic cardiac events in our series, with a low overall perioperative complication rate, comparable to data from the literature . Despite a trend towards a greater decrease in $\mathrm{Hb}$ in the LTP group, only one patient required a transfusion in this group. In the 3 patients transfused after HoLEP, 2 were due to a decreased preoperative $\mathrm{Hb}(<100 \mathrm{~g} / \mathrm{l})$, and 1 due to postoperative bleeding with bladder clot formation in a patient on anticoagulant therapy.

The second objective of minimally-invasive treatments for BPH is to reduce times for catheterization and hospitalization. In this study, laser enucleation would appear to be the less invasive of the two, through its endoscopic approach, its lesser catheterization time and average length of stay, and lower hemoglobin decrease, for an equivalent complication rate. Studies have reported encouraging results for the HoLEP technique in ambulatory surgery [20], which has not been described with the LTP technique. Reducing urinary catheterization in the HoLEP technique seems to be feasible contrary to LTP, which requires a minimal duration of healing.

Patients treated by HoLEP described more urgenturia and pollakiuria than the LTP group, with or without incontinence. These kinds of symptoms decrease with time, and a longer follow up is recommended to correctly analyze hyperactive syndrome complications.

\section{Functional Results}

The functional results at 3 months were better in the LTP group, in agreement with data from the literature $[21,22]$. In fact, we noted a significantly lower IPSS score at 3 months in the group of patients treated laparoscopically, while uroflowmetry was substantially equivalent in both groups. This difference was probably due to a slower decline of voiding problems in the storage phase in the HoLEP group. These irritative voiding symptoms may be increased by the laser energy delivered on contact with the prostatic capsule during endoscopic enucleation. Similarly, the higher PSA observed in patients operated on with the laser could be explained by the persistence of residual prostatic tissue, but also by the laser energy delivered during treatment. Further studies are needed to validate these assumptions.

\section{Economic Impact}

The economic impact of these 2 techniques has not been evaluated. Nevertheless, LTP has the advantage of having equipment already available for those who perform radical laparoscopic prostatectomies. The HoLEP technique involves the purchase of a holmium laser generator and a morcellator, which requires an initial investment, but can be used in lithiasis surgery as well as in prostate surgery. It is likely that this initial extra cost would be quickly offset by gains from the significant reduction in the length of stay of patients operated on by this technique. Juaneda et al. [12] explained in their study that the cost utility analysis for HoLEP per case was 2,589 euros versus 4,706 euros per laparoscopic case. Moreover, the hospitalization cost of HoLEP was 9.6\% less than for open prostatectomy thanks to the length of postoperative hospital stay, and despite of the cost of equipment and operative time [23].

\section{Limitations}

This observational study has several limitations. Due to the retrospective design, some parameters were not collected that may have influenced clinical decisionmaking, such as IPSS or Qmax. As it was a monocentric study, we collected data from a long period in order to provide appropriate analyses. As the numbers of analyzed patients was small and the groups were heterogeneous, our retrospective study can only be regarded as hypothesis-generating, but not as definitive.

\section{Conclusion}

In this preliminary study, there was no increased morbidity for LTP compared to the HoLEP technique. However, the HoLEP technique appeared to be a less invasive technique, reducing blood loss and hospital stay while maintaining good efficacy on the enucleated prostate volume. Prospective randomized medico-economic studies are needed to better assess the role of these two techniques in the therapeutic arsenal, and in particular to clarify their impact on the recovery of patient activity. 


\section{References}

1 Descazeaud A, Robert G, Delongchamps NB, Cornu JN, Saussine C, Haillot O, Devonec $\mathrm{M}$, Fourmarier $\mathrm{M}$, Ballereau $\mathrm{C}$, Lukacs B, Dumonceau O, Azzouzi AR, Faix A, Desgrandchamps F, de la Taille A: Initial assessment, follow-up and treatment of lower urinary tract symptoms related to benign prostatic hyperplasia: guidelines of the LUTS committee of the French Urological Association. Prog Urol 2012;22:977-988.

2 Gratzke C, Bachmann A, Descazeaud A, Drake MJ, Madersbacher S, Mamoulakis C, Oelke M, Tikkinen KA, Gravas S: EAU guidelines on the assessment of non-neurogenic male lower urinary tract symptoms including benign prostatic obstruction. Eur Urol 2015;67:1099-1109.

3 Gilling PJ, Cass CB, Cresswell MD, Fraundorfer MR: Holmium laser resection of the prostate: preliminary results of a new method for the treatment of benign prostatic hyperplasia. Urology 1996;47:48-51.

4 Gilling PJ, Wilson LC, King CJ, Westenberg AM, Frampton CM, Fraundorfer MR: Longterm results of a randomized trial comparing holmium laser enucleation of the prostate and transurethral resection of the prostate: results at 7 years. BJU Int 2012;109:408-411.

5 Sotelo R, Spaliviero M, Garcia-Segui A, Hasan W, Novoa J, Desai MM, Kaouk JH, Gill IS: Laparoscopic retropubic simple prostatectomy. J Urol 2005;173:757-760.

6 Mariano MB, Graziottin TM, Tefilli MV: Laparoscopic prostatectomy with vascular control for benign prostatic hyperplasia. J Urol 2002;167:2528-2529.

7 Stolzenburg JU, Kallidonis P, Qazi H, Ho Thi P, Dietel A, Liatsikos EN, Do M: Extraperitoneal approach for robotic-assisted simple prostatectomy. Urology 2014;84:1099-1105.

8 Dindo D, Demartines N, Clavien PA: Classification of surgical complications: a new proposal with evaluation in a cohort of 6336 patients and results of a survey. Ann Surg 2004;240:205-213.
9 Millin T: Retropubic prostatectomy; a new extravesical technique; report of 20 cases. Lancet 1945;2:693-696.

10 van Velthoven R, Peltier A, Laguna M, Piechaud T: Laparoscopic extraperitoneal adenomectomy (Millin): pilot study on feasibility. Eur Urol 2004;45:103-109.

11 Rehman J, Khan SA, Sukkarieh T, Chughtai B, Waltzer WC: Extraperitoneal laparoscopic prostatectomy (adenomectomy) for obstructing benign prostatic hyperplasia: transvesical and transcapsular (Millin) techniques. J Endourol 2005;19:491-496.

12 Juaneda R, Thanigasalam R, Rizk J, Perrot E, Theveniaud PE, Baumert H: Holmium laser enucleation versus laparoscopic simple prostatectomy for large adenomas. Actas Urol Esp 2016;40:43-48.

13 Rasch A, Gruber S, Perleth M: Learning curve in laser treatment of benign prostatic syndrome: a systematic review. Z Evid Fortbild Qual Gesundhwes 2013;107:335-343.

14 Robert G, Cornu JN, Fourmarier M, Saussine C, Descazeaud A, Azzouzi AR, Vicaut E, Lukacs B: Multicenter prospective evaluation of the learning curve of the holmium laser enucleation of the prostate (HoLEP). BJU Int 2016;117:495-499.

15 Porpiglia F, Terrone C, Renard J, Grande S, Musso F, Cossu M, Vacca F, Scarpa RM: Transcapsular adenomectomy (Millin): a Comparative study, extraperitoneal laparoscopy versus open surgery. Eur Urol 2006;49: 120-126.

16 Roos NP, Wennberg JE, Malenka DJ, Fisher ES, McPherson K, Andersen TF, Cohen MM, Ramsey E: Mortality and reoperation after open and transurethral resection of the prostate for benign prostatic hyperplasia. N Engl J Med 1989;320:1120-1124.
17 Shalev M, Richter S, Kessler O, Shpitz B, Fredman B, Nissenkorn I: Long-term incidence of acute myocardial infarction after open and transurethral resection of the prostate for benign prostatic hyperplasia. J Urol 1999;161:491-493.

18 Hahn RG, Farahmand BY, Hallin A, Hammar N, Persson PG: Incidence of acute myocardial infarction and cause-specific mortality after transurethral treatments of prostatic hypertrophy. Urology 2000;55:236-240.

19 Madersbacher S, Lackner J, Brössner C, Röhlich M, Stancik I, Willinger M, Schatzl G: Reoperation, myocardial infarction and mortality after transurethral and open prostatectomy: a nation-wide, long-term analysis of 23,123 cases. Eur Urol 2005;47:499-504.

20 Gabbay G, Bernhard JC, Renard O, Ballanger P, Ferriere JM, Fallot J, Comat V, Robert G: Holmium laser enucleation of the prostate as a day case surgery: prospective evaluation of the first 30 patients. Prog Urol 2015;25:34-39.

21 Naspro R, Suardi N, Salonia A, Scattoni V, Guazzoni G, Colombo R, Cestari A, Briganti A, Mazzoccoli B, Rigatti P, Montorsi F: Holmium laser enucleation of the prostate versus open prostatectomy for prostates $>70 \mathrm{~g}$ : 24-month follow-up. Eur Urol 2006;50:563568

22 Kuntz RM, Lehrich K, Ahyai SA: Holmium laser enucleation of the prostate versus open prostatectomy for prostates greater than 100 grams: 5-year follow-up results of a randomised clinical trial. Eur Urol 2008;53:160168

23 Salonia A, Suardi N, Naspro R, Mazzoccoli B, Zanni G, Gallina A, Bua L, Scattoni V, Rigatti P, Montorsi F: Holmium laser enucleation versus open prostatectomy for benign prostatic hyperplasia: an inpatient cost analysis. Urology 2006;68:302-306. 